\title{
Serum Amino Acid Pattern of Type II Citrullinemic Patients and Effect of Oral Administration of Citrulline
}

\author{
Takeyori SAHEKI, ${ }^{1, *}$ Keiko Kobayashi, ${ }^{1}$ Tsutomu Miura, ${ }^{2}$ \\ Shuji Hashimoto, ${ }^{2}$ Yukihisa Ueno, ${ }^{3}$ Toshihiro YamasaKi, ${ }^{3}$ \\ Hirotake Araki, ${ }^{4}$ Hidehasu NARA, ${ }^{5}$ Yasuko ShIOZAKI ${ }^{6}$ \\ Yoshiko Sameshima, ${ }^{6}$ Masayoshi Suzuki, ${ }^{7}$ Yasuhiko Yamauchi, ${ }^{8}$ \\ Yoshiki SaKazume, ${ }^{9}$ Kenji AkIYama, ${ }^{10}$ and Yoshinori Yamamura ${ }^{11}$ \\ ${ }^{1}$ First Department of Biochemistry and ${ }^{2}$ Second Department of Internal Medicine, \\ School of Medicine, Kagoshima University, Kagoshima 890, Japan \\ ${ }^{3}$ Kawasaki Central Hospital, Kawasaki 210, Japan \\ ${ }^{4}$ Sayama Neurology Hospital, Sayama 350-13, Japan \\ ${ }^{5}$ Aomori Rosai Hospital, Hachinohe 031, Japan \\ ${ }^{6}$ Third Department of Internal Medicine, Kansai Medical University, Moriguchi 570, Japan \\ ${ }^{7}$ Department of Pediatrics, Medical College of Oita, Hazama-cho, Oita 879-56, Japan \\ ${ }^{9}$ National Takasaki Hospital, Takasaki 370, Japan \\ ${ }^{9}$ Fourth Department of Internal Medicine, Saitama Medical School, \\ Moroyama-cho, Saitama 350-04, Japan \\ ${ }^{10}$ Second Department of Internal Medicine, Asahikawa Medical College, \\ Asahikawa 078-11, Japan \\ ${ }^{11}$ Third Department of Internal Medicine, Miyazaki Medical College, \\ Kiyotake-cho, Miyazaki 889-16, Japan
}

(Received February 10, 1986)

Summary Twenty-four cases of type II citrullinemia, diagnosed as such based on enzymatic analysis showing a decreased enzyme content of kinetically-normal argininosuccinate synthetase in the liver, showed the following features of their serum amino acid patterns: 1) Serum arginine levels were higher than in controls and were significantly correlated with serum citrulline levels. 2) Serum alanine, serine, glycine, and branchedchain amino acids (valine + isoleucine+leucine) were significantly lower than in the controls, while threonine was rather higher and aromatic amino acids (tyrosine + phenylalanine) remained at the control level. Thus the ratio of threonine to serine and of branched-chain amino acids to aromatic amino acids were characteristically higher and lower than the control values, respectively.

The above characteristics were quite unique to type II citrullinemia and not found in serum amino acid patterns of type I and III citrullinemic patients. Examination of effect of oral administration of citrulline

*To whom correspondence should be addressed. 
on the amino acid pattern was also showed that the decrease of serum citrulline after the administration was delayed in type II citrullinemic patients; which was, however, not specific to type II citrullinemia, but was also found in patients with liver cirrhosis and chronic nephritis, and more prominently in one type III citrullinemic patient. After citrulline administration, serum arginine was increased in type II citrullinemic patients as much as in the healthy controls, but was decreased in the type III patient. The increase in serum ornithine after citrulline administration in the type II patients and in the parents of the type III patient (considered to be heterozygotes) was about half of the control value, but that in patients with liver cirrhosis was greater than the control. The ratios of threonine to serine and branched-chain amino acids to aromatic amino acids were not altered by the citrulline administration.

Key Words: citrullinemia, argininosuccinate synthetase, serum amino acids, citrulline, arginine

Citrullinemia, first described by McMurray et al. [1], is a rare hereditary disorder caused by deficient activity of argininosuccinate synthetase (ASS). In Japan, however, many cases of citrullinemia distinct from the classical neonatalonset type described by McMurray et al. have been found, and they have some unique characteristics concerning the clinical picture, enzyme abnormalities, and so on [2-4]; for example, the disease has been found in adults suffering from disturbances of consciousness. From the enzymatic analyses of about 50 cases of the latter and classical citrullinemic patients, Saheki et al. [5] classified them into three types: in type I citrullinemic patients or the qualitative type according to our earlier classification and in type III, which are seen mostly in neonates or infants and seem to belong to the classical citrullinemia category, a kinetically abnormal ASS and almost no ASS protein, respectively, were found in the liver, kidney, and cultured skin fibroblasts. On the contrary, in type II citrullinemia or the quantitative type, to which most of the adult citrullinemic patients belong, the enzyme abnormality involving a decreased enzyme content was seen in the liver, but not in the kidney and cultured skin fibroblasts. Furthermore, we found a normal amount of mRNA coding for ASS in the liver of type II citrullinemic patients, as judged from analysis with a cell-free translation system and dot hybridization with cDNA for ASS [6, 7], suggesting that the decrease of ASS in the liver may be caused by an increased degradation or a decreased translation of the enzyme.

As for an abnormality in amino acids except citrulline in citrullinemic patients, there have been a few papers which reported arginine deficiency and homocitrulline and homoarginine excretion $[8,9]$. Some arginine levels in most of adult 
citrullinemic patients in Japan, however, have been described to be rather higher than those of the controls. We found that this discrepancy in serum arginine is related to the type of enzyme abnormality in citrullinemia and reported it in a preliminary paper [10].

In this paper, we describe features of the serum amino acid pattern of citrullinemic patients (especially of type II ones) found during the analysis of about 40 cases of the patients, and the effect of oral administration of citrulline on them.

\section{MATERIALS AND METHODS}

Patients. The citrullinemic patients diagnosed as either of the three types by the enzymatic analyses of urea cycle enzymes in the liver are described in this paper. Data on serum amino acids shown in Figs. 1 and 2 were obtained from published papers [11-18] or personally communicated. Data about the patients' sex, age, and hepatic ASS activity are given in Table 1. Clinical data of adult citrullinemic patients (AP) \#13, 17, 25, 30, 31, 33, 35, and 37, and of an infantile patient (IP) $\# 7$, who were subjected to oral administration test of citrulline, have been published [16] or will be published elsewhere. The activities of the other enzymes of the urea cycle in the livers of AP \#17 and 30, and of IP \#7, were published by Kobayashi et al. [7]. As the control, serum amino acid levels were determined for 8 healthy subjects ( 2 females and 6 males, ranging in ages from 20 to 50 years). And for comparison, the levels in patients with chronic hepatitis $(n=5)$, liver cirrhosis (16), or chronic nephritis (10) were also examined.

The diagnoses were made from laboratory findings.

Oral administration of citrulline. Citrulline (Nakarai Chemicals, Ltd., Kyoto, Japan), $100 \mathrm{mg} / \mathrm{kg}$ body weight, was administered in 100 to $200 \mathrm{ml}$ of water to healthy controls $(n=8)$, citrullinemic patients $(n=7)$, and to patients with liver cirrhosis $(n=5)$ or chronic nephritis $(n=1)$ at 9-10 a.m. after overnight fasting. Serum samples were prepared before the administration and afterwards at hourly intervals over a $4 \mathrm{~h}$ period. We observed no harmful effects during the oral administration of citrulline except that a slight increase in serum bilirubin was seen in patients with liver cirrhosis.

Amino acid analysis. After the deproteinization of serum and urine with sulfosalicylic acid (final concentration, 2.5\%), amino acid analysis was performed with a Hitachi 835 Amino Acid Analyzer (Hitachi, Japan).

\section{RESULTS}

\section{Serum amino acid pattern of type II citrullinemic patients}

Citrulline. Adult citrullinemic patients were found by laboratory examinations to have hyperammonemia and high serum citrulline without significant liver damage and portacaval shunts among patients suffering from a sudden dis- 
Table 1. List of citrullinemic patients whose serum amino acid patterns are described in the present paper.

\begin{tabular}{|c|c|c|c|c|}
\hline Patient (name) & Age & Sex & $\begin{array}{l}\text { Hepatic ASS } \\
\text { activity }(\%)\end{array}$ & $\begin{array}{c}\text { Type of enzyme } \\
\text { abnormality }\end{array}$ \\
\hline $\mathrm{AP} \# 2(\mathrm{KK})$ & 46 & $\mathrm{~m}$ & 1.5 & II \\
\hline $3(\mathrm{HH})$ & 24 & $\mathrm{f}$ & 4.8 & $\mathrm{I}$ \\
\hline $5(\mathrm{SN})$ & 18 & $\mathrm{~m}$ & 29 & II \\
\hline 6 (MT) & 26 & $\mathrm{f}$ & 46 & I (?) \\
\hline 10 (HM) & 20 & $\mathrm{~m}$ & 13 & II \\
\hline $12(\mathrm{KI})$ & 29 & $\mathrm{~m}$ & 19 & II \\
\hline $13(\mathrm{KM})$ & 21 & $\mathrm{~m}$ & 45 & II \\
\hline 14 (MU) & 42 & $\mathrm{~m}$ & 13 & II \\
\hline $17(\mathrm{KO})$ & 40 & $\mathrm{f}$ & 19 & II \\
\hline 18 (TK) & 33 & $\mathrm{~m}$ & 6.9 & II \\
\hline 22 (TK) & 31 & $\mathrm{~m}$ & 12 & II \\
\hline 24 (TM) & 18 & $\mathrm{~m}$ & 11 & II \\
\hline 25 (TS) & 43 & $\mathrm{f}$ & 14 & II \\
\hline 27 (KA) & 40 & $\mathrm{~m}$ & 9.3 & II \\
\hline $28(\mathrm{TK})$ & 40 & $\mathrm{~m}$ & 49 & II \\
\hline 29 (KA) & 23 & $\mathrm{~m}$ & 8.2 & II \\
\hline 30 (US) & 19 & $\mathrm{f}$ & 14 & II \\
\hline $31(\mathrm{HN})$ & 32 & $\mathrm{~m}$ & 40 & II \\
\hline 33 (SM) & 31 & $\mathrm{~m}$ & 21 & II \\
\hline $34(\mathrm{TY})$ & 48 & $\mathrm{f}$ & 36 & II \\
\hline 35 (HS) & 48 & $\mathrm{~m}$ & 17 & II \\
\hline $37(\mathrm{HK})$ & 42 & $\mathrm{~m}$ & 25 & II \\
\hline $38(\mathrm{KH})$ & 35 & $\mathrm{~m}$ & 9.5 & II \\
\hline $39(\mathrm{YT})$ & 31 & $\mathrm{~m}$ & 13 & II \\
\hline IP \# 1 (MA) & $24 \mathrm{~d}$ & $\mathrm{f}$ & 1 & I \\
\hline $2(\mathrm{IT})$ & $21 \mathrm{~d}$ & $\mathrm{f}$ & 0 & III \\
\hline $4(F)$ & $3 \mathrm{~d}$ & f & 0 & III \\
\hline 5 (SM) & $10 \mathrm{~m}$ & f & 25 & II \\
\hline $6(\mathrm{RT})$ & 12 & $\mathrm{f}$ & 12 & II \\
\hline $7(\mathrm{JU})$ & $8 \mathrm{~m}$ & $\mathrm{f}$ & 0 & III \\
\hline 8 (TS) & $8 \mathrm{~m}$ & $\mathrm{~m}$ & 3 & $\mathrm{I}$ \\
\hline 9 (NS) & $8 \mathrm{~m}$ & $\mathrm{~m}$ & 1.3 & I \\
\hline 11 (HA) & $4 d$ & $\mathrm{~m}$ & 0 & III \\
\hline
\end{tabular}

Patients were classified and are expressed as adult patients (AP) or infantile or neonatal patients (IP). Age is expressed in years except in the case of IP's when it is given in days (d) or months $(\mathrm{m}) . \mathrm{m}$ and $\mathrm{f}$ denote male and female, respectively. Hepatic ASS activity is expressed as $\%$ of the adult control mean value $(0.84 \mathrm{U} / \mathrm{g}$ liver) or of the neonate (below 3 months old) control mean value $(0.21 \mathrm{U} / \mathrm{g}$ liver). Type of enzyme abnormality was determined by the kinetic properties of ASS and the content of ASS protein measured immunologically $[2,5]$.

turbance of consciousness, or from convulsion, vomiting and mental retardation from childhood. Almost all of the adult patients were diagnosed as having type II citrullinemia on the basis of the enzymatic analysis of ASS.

Figure 1 shows general features of amino acids in the serum of 24 adult 


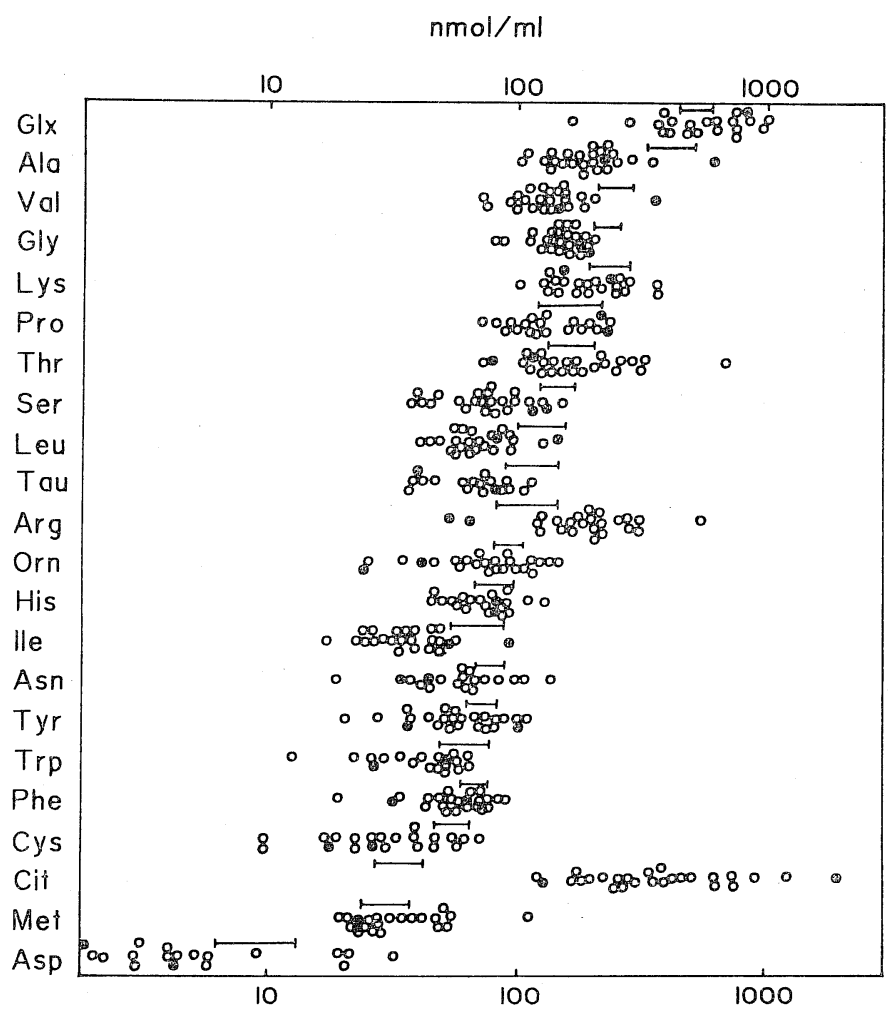

Fig. 1. General features of serum amino acids of adult citrullinemic patients who were diagnosed upon enzymatic analysis as type I (20) or type II (O). Bars in the figure indicate the ranges of serum amino acids of healthy controls. List of the patients is shown in Table 1.

citrullinemic patients whose enzymatic analysis was performed in Department of Biochemistry (Kagoshima University). The data with which these patients were suspected of citrullinemia are shown in Fig. 1. Serum citrulline levels in type II citrullinemic patients ( 24 cases) usually ranged from 150 to $1,000 \mathrm{nmol} / \mathrm{ml}$ (control, 20 to $40 \mathrm{nmol} / \mathrm{ml}$ ), being somewhat lower than those of neonatal citrullinemic patients $(1,000$ to $4,000 \mathrm{nmol} / \mathrm{ml})$. The levels, however, tended to change considerably during the clinical course (see also Fig. 4). A high level of serum citrulline was observed in an adult patient who was shown to have a kinetically abnormal ASS in the liver and in cultured skin fibroblasts (type I citrullinemia).

As far as we have tested, none of hepatic diseases, including acute hepatitis, chronic hepatitis, liver cirrhosis, and primary hepatoma, showed citrulline levels higher than $100 \mathrm{nmol} / \mathrm{ml}$. However, slightly higher levels $(\sim 115 \mathrm{nmol} / \mathrm{ml})$ were observed in patients with chronic nephritis. Aside from citrullinemia, considerably high levels of citrulline were observed in patients with argininosuccinic aciduria (data not shown). 
Arginine. Type II citrullinemic patients showed high levels of arginine (Fig. 1 ), which were significantly correlated with serum citrulline levels $(r=0.81)$, as shown in Fig. 2. On the contrary, arginine levels in type I and III citrullinemic patients (mostly neonates or infants) were lower than those of controls, as described in the literature $[8,9]$.

Other amino acids. Some of the other serum amino acids, alanine, glycine, serine and branched-chain amino acids (BCAA), of type II citrullinemic patients

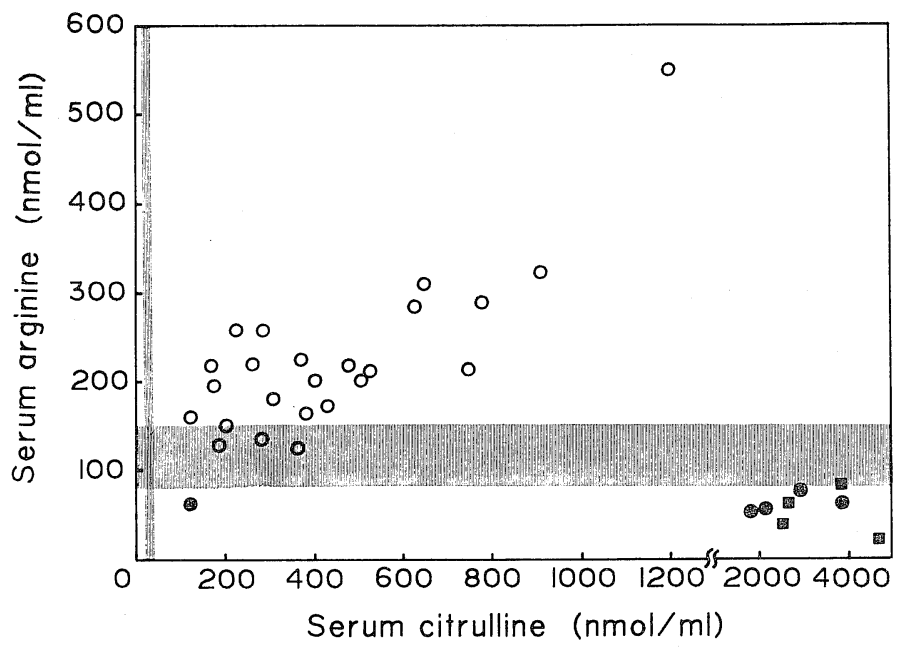

Fig. 2. Relation between serum citrulline and arginine of type I ( $)$ ), II (O), and III ( citrullinemic patients. Except for two type I patients, all of the type I and III patients shown in the figure were neonates or infants below 8 months old. Shaded areas indicate control ranges of serum citrulline and arginine.

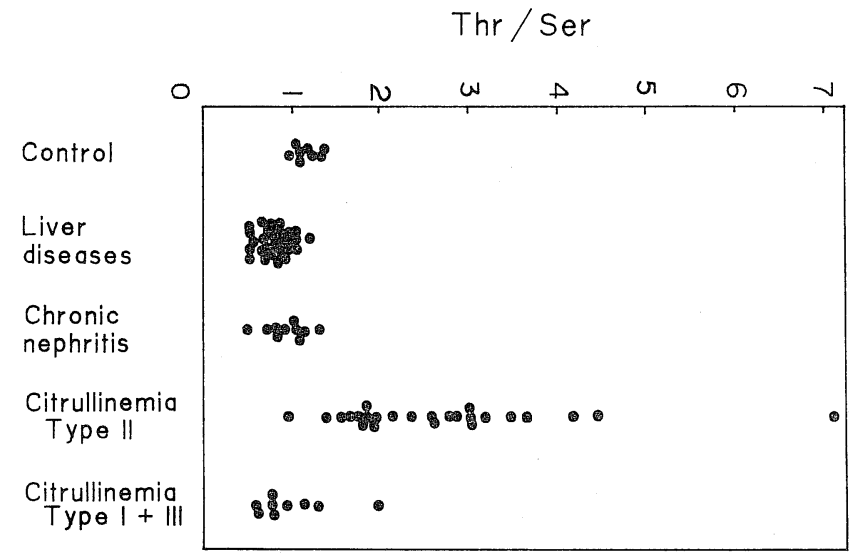

Fig. 3. Ratio of serum threonine to serine of controls and of patients with liver diseases including chronic hepatitis and liver cirrhosis, with chronic nephritis, and with citrullinemia. 
showed significant decreases as compared with the controls (Fig. 1). The most prominent was the decrease of serum alanine. The level was about $40 \%$ of the control $(185 \pm 87 \mathrm{nmol} / \mathrm{ml}$ vs. the control value of $416 \pm 87 \mathrm{nmol} / \mathrm{ml}$, expressed as mean $\pm \mathrm{SD}$ ). The decrease of alanine was significantly correlated with that of serine $(r=0.68)$ and with sum of BCAA $(r=0.67)$. Among the decreases, two ratios are notable: threonine/serine and $\mathrm{BCAA} /$ tyrosine + phenylalanine. The

Table 2. Levels of serum branched-chain amino acids (BCAA) and aromatic amino acids (AAA), and their ratio (BCAA/AAA) in healthy controls, type II citrullinemic patients, and patients with liver diseases and chronic nephritis.

\begin{tabular}{lllcc}
\hline & $(n)$ & BCAA & AAA & BCAA/AAA \\
\hline Healthy control & $(8)$ & $467 \pm 57$ & $136 \pm 12$ & $3.42 \pm 0.33$ \\
Type II citrullinemia & $(24)$ & $239 \pm 61$ & $136 \pm 12$ & $1.96 \pm 0.51$ \\
Chronic hepatitis & $(5)$ & $417 \pm 78$ & $162 \pm 29$ & $2.64 \pm 0.58$ \\
Liver cirrhosis & $(16)$ & $368 \pm 89$ & $196 \pm 37$ & $1.90 \pm 0.48$ \\
Chronic nephritis & $(10)$ & $396 \pm 110$ & $166 \pm 31$ & $2.41 \pm 0.67$ \\
\hline
\end{tabular}

Sum of valine, leucine, and isoleucine was expressed as BCAA; and sum of tyrosine and phenylalanine, as AAA. Values are means \pm SD for the number of observations (given in parentheses).

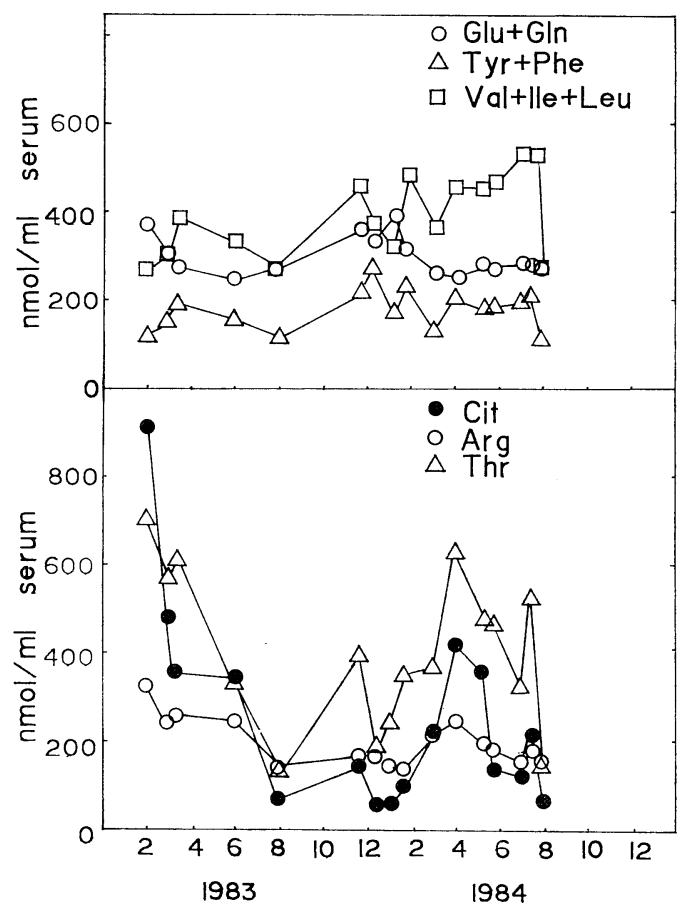

Fig. 4. Changes in serum levels of citrulline, arginine, threonine, and some other amino acids of an adult patient, AP \#25, during her clinical course from February 1983 to August 1984. 
ratio of two hydroxy-amino acids, threonine to serine (Thr/Ser), was significantly higher in type II citrullinemics $(2.68 \pm 1.28)$ than in controls (Fig. 3). The Thr/Ser ratio in healthy controls was about unity $(1.17 \pm 0.13)$, and those in patients with chronic hepatitis $(0.82 \pm 0.10)$, liver cirrhosis $(0.81 \pm 0.20)$, or chronic nephritis $(0.95 \pm 0.24)$ were rather slightly lower. The higher $\mathrm{Thr} / \mathrm{Ser}$ ratio seems to result mainly from lower serine levels $(76.4 \pm 28.9 \mathrm{nmol} / \mathrm{ml}$ vs. $140 \pm 20 \mathrm{nmol} / \mathrm{ml})$, but also partly from higher threonine levels $(200 \pm 129 \mathrm{nmol} / \mathrm{ml} v s .163 \pm 30 \mathrm{nmol} / \mathrm{ml})$ in the serum of type II citrullinemic patients. That in 2 adult cases of type I was lower than unity, but that in neonatal cases of type I and III was variable.

The other is a lower ratio of BCAA (valine + leucine + isoleucine) to AAA (aromatic amino acid, tyrosine + phenylalanine), BCAA/AAA, in type II citrullinemic patients than in healthy controls (Table 2). The lower BCAA/AAA ratio, which was comparable with that in patients with liver cirrhosis, resulted from the decreased level of BCAA, while that of AAA remained unchanged. This means that the low BCAA/AAA ratio in type II citrullinemic patients is caused by a mechanism distinct from that in liver damages.

\section{Follow-up study of a case about serum amino acids}

The serum amino acid pattern of one case, an adult citrullinemic patient \#25, was followed up for more than a year. Figure 4 illustrates changes in citrulline, arginine, and threonine as well as in glutamine + glutamate, BCAA, and AAA in the serum of the patient. Serum citrulline changed markedly during the period in close correlation with arginine $(r=0.84)$ and threonine $(r=0.81)$. A similar correlation was also observed between citrulline and $\mathrm{Thr} / \mathrm{Ser}$ ratio $(r=0.81)$. On the contrary, there was no correlation between citrulline and glutamine + glutamate, BCAA, AAA, or BCAA/AAA ratio.

\section{Effects of oral administration of citrulline on serum amino acids}

To clarify whether the changes in serum amino acids listed above were caused by the high serum citrulline levels or not, and to examine their specificity and possibility for use as markers to differentiate type II from types I and III, we administered citrulline orally to healthy controls and citrullinemic patients. The serum amino acid profile of type II citrullinemic patients just before citrulline administration showed the features listed above.

Figure 5 shows time courses of changes in serum citrulline after citrulline administration. As compared with healthy controls (the range indicated by the shaded area), the decrease of serum citrulline in type II citrullinemic patients was delayed, which was quantified as half time of the decrease as shown in Table 3. In an infantile case of type III citrullinemic (IP \#7), in which there was no detectable ASS activity in the liver and possibly none in the kidney [5], the half-time value was markedly larger than those in type II patients. The decrease in serum citrulline was also delayed in patients with liver cirrhosis or chronic nephritis.

After the oral administration of citrulline, serum arginine was increased in 


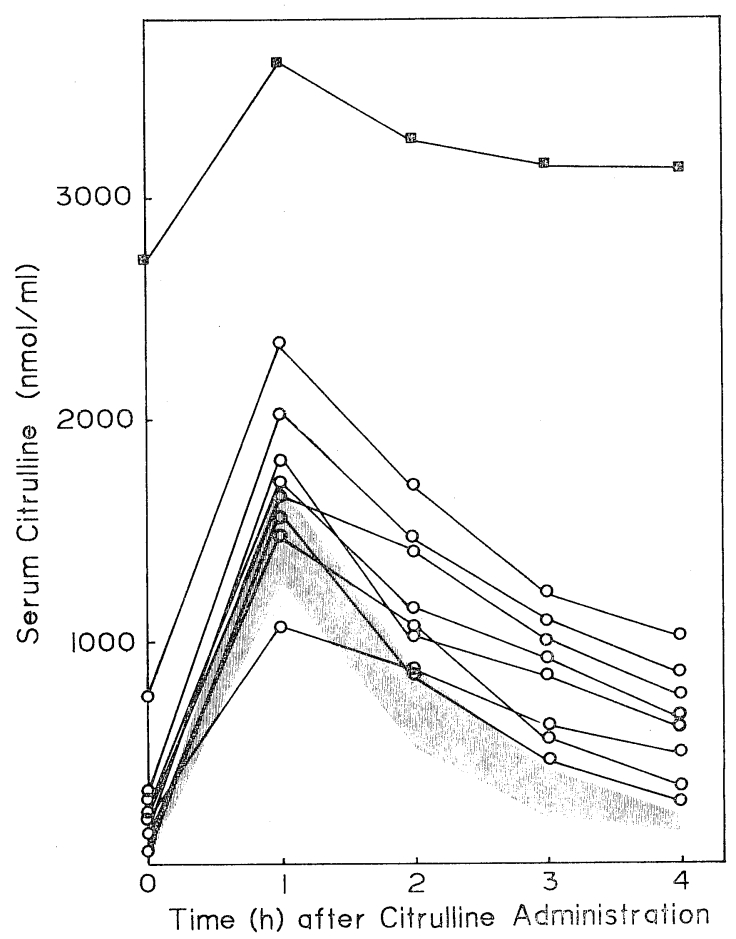

Fig. 5. Changes in serum citrulline of control and citrullinemic patients after oral administration of citrulline. Citrulline, $100 \mathrm{mg} / \mathrm{kg}$ body weight, was administered orally between 9 and 10 a.m. after overnight fasting. Eight type II (O) and one type III (圂) citrullinemic patients were examined. List of the patients is shown in Table 3. Shaded area shows the control range.

healthy controls and also in type II citrullinemic patients, while it was decreased in a type III citrullinemic patient. The maximum increment within $4 \mathrm{~h}$ was slightly lower in type II citrullinemic patients than in the controls $(p<0.1)$. This may, however, be derived from the rather higher arginine levels at 0 -time of the patients, for there was no difference in the maximum levels of serum arginine after the administration between the control $(260 \pm 46 \mathrm{nmol} / \mathrm{ml})$ and the type II citrullinemic patients $(273 \pm 47 \mathrm{nmol} / \mathrm{ml})$.

After the oral administration of citrulline, serum serine and BCAA of healthy controls and citrullinemic patients were decreased. But since serum threonine and AAA were decreased simultaneously and to the same extent, the ratios of $\mathrm{Thr} / \mathrm{Ser}$ and BCAA/AAA were not altered (data not shown), suggesting that neither the increase in $\mathrm{Thr} / \mathrm{Ser}$ ratio nor the decrease in BCAA/AAA ratio seen in the serum of type II citrullinemic patients is caused by the direct effect of high serum citrulline. The change in serum alanine after the administration was variable.

Another interesting observation found during the tests was the changes in serum ornithine (Table 3 ); the increment of serum ornithine was not seen in the 
Table 3. Changes in serum citrulline, arginine, and ornithine levels after oral administration of citrulline.

\begin{tabular}{|c|c|c|c|c|c|c|c|}
\hline \multirow[b]{3}{*}{$\begin{array}{c}\text { Control } \\
n=8\end{array}$} & \multicolumn{3}{|c|}{ Citrulline } & \multicolumn{2}{|c|}{ Arginine } & \multicolumn{2}{|c|}{ Ornithine } \\
\hline & 0-time & $\begin{array}{l}\Delta \mathrm{Cit} \\
\mathrm{ol} / \mathrm{ml})\end{array}$ & \multirow{2}{*}{$\begin{array}{c}\begin{array}{c}\text { Rate of } \\
\text { decrease } \\
\text { (min) }\end{array} \\
55 \pm 6 \\
(44-65)\end{array}$} & \multirow{2}{*}{$\begin{array}{c}0 \text {-time } \\
\text { (nmo } \\
118 \pm 24 \\
(79-148)\end{array}$} & \multirow{2}{*}{$\begin{array}{l}\Delta \mathrm{Arg} \\
/ \mathrm{ml}) \\
143 \pm 38 \\
(77-186)\end{array}$} & \multirow{2}{*}{$\begin{array}{c}0 \text {-time } \\
\text { (nmo } \\
\begin{array}{c}93 \pm 9 \\
(73-107)\end{array}\end{array}$} & \multirow{2}{*}{$\begin{array}{l}\Delta \text { Orn } \\
\begin{array}{c}1 / \mathrm{ml}) \\
91 \pm 23 \\
(79-106)\end{array}\end{array}$} \\
\hline & $\begin{array}{c}36 \pm 7 \\
(26-42)\end{array}$ & $\begin{array}{c}1,500 \pm 160 \\
(1,230-1,680)\end{array}$ & & & & & \\
\hline \multicolumn{8}{|l|}{$\begin{array}{l}\text { Citrullinemia } \\
\text { Type II }\end{array}$} \\
\hline AP \# 13 & 62 & 1,560 & 72 & 150 & 105 & 60 & 18 \\
\hline 17 & 226 & 1,440 & 140 & 182 & 71 & 84 & 47 \\
\hline 25 & 144 & 1,330 & 78 & 169 & 62 & 76 & 31 \\
\hline 30 & 334 & 1,680 & 147 & 239 & 114 & 102 & 114 \\
\hline 31 & 758 & 1,580 & 132 & 139 & 109 & 220 & 18 \\
\hline 33 & 204 & 873 & 156 & 171 & 105 & 138 & 48 \\
\hline 35 & 296 & 1,420 & 125 & 124 & 169 & 52 & 44 \\
\hline 37 & 214 & 1,600 & 147 & 152 & 125 & 97 & 1 \\
\hline$n=8$ & $280 \pm 211$ & $1,440 \pm 254$ & $125 \pm 32$ & $166 \pm 35$ & $108 \pm 33$ & $104 \pm 54$ & $40 \pm 34$ \\
\hline \multicolumn{8}{|l|}{ Type III } \\
\hline IP \# 7 & 2,710 & 890 & 380 & 67 & -14 & 29 & -10 \\
\hline Father of IP\#7 & 36 & 1,070 & 45 & 79 & 106 & 52 & 47 \\
\hline Mother of IP\#7 & 33 & 1,220 & 52 & 107 & 112 & 49 & 58 \\
\hline $\begin{array}{l}\text { Liver } \\
\text { cirrhosis } \\
n=5\end{array}$ & $\begin{array}{l}39 \pm 14 \\
(33-64)\end{array}$ & $\begin{array}{c}1,280 \pm 180 \\
(1,060-1,510)\end{array}$ & $\begin{array}{c}91 \pm 34 \\
(51-129)\end{array}$ & $\begin{array}{l}125 \pm 55 \\
(38-187)\end{array}$ & $\begin{array}{c}144 \pm 18 \\
(133-173)\end{array}$ & $\begin{array}{c}76 \pm 25 \\
(39-106)\end{array}$ & $\begin{array}{l}125 \pm 23 \\
(90-147)\end{array}$ \\
\hline $\begin{array}{l}\text { Chronic } \\
\qquad \begin{array}{l}\text { nephritis } \\
n=1\end{array}\end{array}$ & 49 & 750 & 168 & 94 & 138 & 62 & 96 \\
\hline
\end{tabular}

Numbers in parentheses indicate the range of the values. $\Delta$ indicates difference between the value at 0 -time and the maximum or minimum value after the citrulline administration. Rate of decrease in citrulline is expressed as half-time of the decrease $\left(t_{1 / 2}\right)$ calculated on a semilogarithmic graph.

type III citrullinemic patient and was considerably lower $(p<0.01)$ in type II citrullinemic patients (except for one case) than in the control. The parents of the type III infant, considered to be heterozygotes, showed increments of about a half of the control value.

\section{DISCUSSION}

The profiles of the serum amino acids listed in this paper are unique to type II citrullinemia, although precise comparison with those of neonatal-type, or type I, and III citrullinemia is difficult because of the difference in ages between the patients.

The very high levels of serum citrulline generally found in type I or III citrul- 
linemic patients are thought to result mainly from a highly deficient ASS activity in both the liver and the kidney of the patients. It is remarkable that the citrulline level in type II citrullinemic patients varies so much during the clinical course (see Fig. 4). This may be related to the general state of the patients, catabolic or not, which is also reflected in the levels of the other amino acids as will be mentioned later.

Measurement of the rate of decrease in serum citrulline after the oral administration of citrulline has been used as a clinical test for citrullinemia [17, 19]. But there are no reports as to whether the delay of serum citrulline decrease is found specifically in citrullinemia or not. The changes in serum citrulline after the oral administration of citrulline represent overall processes of citrulline metabolism including the absorption from the intestine, the metabolism in the liver and kidney, and the excretion. The increment of citrulline in the serum $1 \mathrm{~h}$ after the administration was not so different among the control subjects and type II citrullinemic patients except for one case, suggesting similar amounts and rates of absorption.

But it is difficult to discuss separately the three processes. The delayed decrease of serum citrulline might represent some inhibition of the renal excretion. This may especially be true for the delay in patients with renal failure. In any event, it was shown that the delay of the decrease in serum citrulline after the oral citrulline administration was not specific to type II citrullinemia. We also showed that the level of serum arginine was markedly different depending on the type of citrullinemia; serum arginine was elevated coordinately with citrulline in type II citrullinemic patients, while it was lower in the type I or III patients than in the controls. This may be explained by a fairly well accepted theory that arginine biosynthesis from citrulline occurs in the kidney [20,21] and by differences in ASS activity in the kidney of citrullinemic patients among the three types. Namely, arginine is synthesized from citrulline by the catalytic action of ASS and argininosuccinase in the kidney. In the case of type I and III citrullinemia, the serum citrulline accumulated cannot be converted to arginine because of a deficient ASS activity in the kidney, while it can be efficiently converted to arginine in type II citrullinemic patients since they have the normal level of kidney ASS activity. This hypothesis is first supported by the close correlation between serum citrulline and arginine levels in 24 type II citrullinemic patients (Fig. 2) and in patient \#25 during the clinical course (Fig. 4). Furthermore, it is confirmed by the results of the oral administration test of citrulline which showed that serum arginine levels were increased in type II citrullinemic patients as much as in healthy controls, but not in the type III citrullinemic patient. Data similar to ours have been obtained for AP \#14 by J. Itoh et al. (personal communication).

The low level of serum alanine seems to be unique to type II citrullinemia; rather high levels were reported in patients with congenital hyperammonemia caused by deficiencies of carbamylphosphate synthetase and ornithine transcarbamylase, and even in neonatal citrullinemics [9]. Although we now have no clear explanation for decreases in serum alanine, serine, glycine and BCAA, and the 
slight increase in serum threonine in type II citrullinemic patients, the phenomena may be partly interpreted as follows: protein catabolism, followed by metabolism of amino acids, especially those which are actually degraded for energy production is stimulated. In turn, this produces much waste nitrogen which is converted into citrulline. Threonine, whose metabolism is considered to be less active, tends to accumulate.

This interpretation may be supported by the following data: the cumulative data of 24 type II citrullinemic patients showed that the decreases in serum amino acids listed above were significantly correlated with each other $(r=0.68$ for serine and alanine, 0.67 for alanine and BCAA, 0.60 for serine and glycine); in the followup study of one type II patient, serum citrulline was correlated with threonine and arginine, as described in "Results," but reversely with alanine $(r=-0.63)$; alanine was correlated with BCAA $(r=0.73)$.

Low levels of serum alanine and BCAA very similar to those of type II citrullinemic patients were found in subjects starved for a long period, such as so-called "boat people" (Gushiken and Saheki, unpublished data). They showed, however, a low level of threonine together with $\mathrm{Thr} /$ Ser rather lower than unity and a high level of phenylalanine, which were quite different from those of type II citrullinemic patients.

It is unlikely that serum citrulline levels directly influence the serum levels of serine, glycine, alanine, and BCAA, since the levels of these amino acids were not constantly decreased by the citrulline administration and were not low in type I and III citrullinemia even though the serum citrulline was usually very high.

The changes in serum ornithine after the citrulline administration may be meaningful. Since ornithine is formed from citrulline via the urea cycle in the liver or after its conversion to arginine in the kidney, the increment of ornithine after citrulline administration may be useful as an indicator of the in vivo activity of the urea cycle. This may be supported by the fact that the parents of the type III patient showed an ornithine increment of about a half of the control value. But we could not find any parallelism between the hepatic ASS activity and the increment of serum ornithine of type II citrullinemic patients; and the parents of the type I citrullinemic patient (IP \#9) tested by G. Takada and co-workers showed an increment of serum ornithine comparable with the control value (personal communication). It is evident that more work is necessary for clarification of the meaning of the changes in serum ornithine.

We have found that type II citrullinemia can be classified further into two subtypes by examining the intralobular hepatic distribution of ASS by immunohistochemical means [22]. One is the homogeneous type, in which most of the hepatocytes within a lobulus are stained homogeneously with antiserum to ASS as in the control liver; and the other, the heterogeneous type, in which positivelystained hepatocytes are disseminated among the poorly-stained cells or form clusters in the midst of the poorly-stained cells. The fatality of the citrullinemic 
patients who belong to the latter (heterogeneous) type is much higher than that of the homogeneous type [23]. We could find no difference between these subtypes in terms of serum amino acid profile.

In conclusion, features of serum amino acids in type II citrullinemic patients, such as arginine, Thr/Ser, and BCAA/AAA, and the characteristic changes in citrulline, arginine, and ornithine levels after the oral administration of citrulline to the patients are useful for diagnosis and may be valuable for the further understanding of the pathogenesis of type II citrullinemia.

This work was done in cooperation with the following clinical investigators: AP \# 2, Drs. M. Yamauchi and F. Fujisawa (Jikei University); \# 3, Dr. N. Yamada (Kitasato University); \# 5 and 10, Dr. K. Kobayashi (Tohoku University); \# 6 and 18, Drs. Y. Suzuki, K. Furuta, and S. Furuta (Shinshu University); \# 12, Dr. N. Kiryu (Yamagata Central Hospital); \# 14 and IP \# 1, Drs. J. Itoh, H. Morishita, and Y. Wada (Nagoya City University); AP \# 22 and IP \# 5, Drs. Y. Itakura, A. Tsuchiyama, and K. Oyanagi (Sapporo Medical College); Ap \# 27, Dr. O. Hashimoto (Gifu University); \# 28, Dr. S. Aoshima (National Shizuoka Hospital); \# 29, Drs. T. Takagi and R. Kasukawa (Fukushima Medical College); \# 34, Dr. H. Sando (National Medical Center of Hospital); \# 38, Dr. M. Ikeda (Kanto Teishin Hospital); \# 39, Dr. M. Kanei (Tonami General Hospital); IP \# 2, Dr. M. Matsuo (Kobe Children's Hospital); \# 4, Drs. Y. Maeda and T. Hosoyamada (Fukuoka Red Cross General Hospital); \# 6, Drs. Y. Nakazato, E. Okano, and H. Takahashi (Kanazawa Medical College); \# 8, Drs. Nagano and S. Arashima (Hokkaido University); \# 9, Dr. G. Takada (Akita University); \# 11, Drs. O. Nukada, C. Uchiyama, and Y. Yoda (Okayama Red Cross General Hospital).

We thank Drs. S. Hagihara, T. Noda, I. Inoue, and S. Matuo for assaying the urea cycle enzymes, by which a specific decrease in ASS activity was confirmed, and Ms. M. Fujii for preparing the manuscript.

This work was supported in part by the Special Project Research Grant No. 60127010 (Inborn Errors of Metabolism) from the Ministry of Education, Science and Culture of Japan.

\section{REFERENCES}

1. McMurray, W.C., Mohyuddin, F., Rossiter, R.J., Rathbun, C., Valentine, G.H., Koegler, S.J., and Zarfas, D.E. (1962): Citrullinemia, a new amino aciduria associated with mental retardation. Lancet, 1, 138.

2. Saheki, T., Ueda, A., Hosoya, M., Takada, S., Tsuda, M., and Katsunuma, T. (1981): Qualitative and quantitative abnormalities of argininosuccinate synthetase in citrullinemia. Clin. Chim. Acta, 109, 325-335.

3. Saheki, T., Ueda, A., Hosoya, M., Sase, M., Nakano, K., and Katsunuma, T. (1983): Enzymatic analysis of citrullinemia (12 cases) in Japan. Urea cycle diseases. Adv. Exp. Med. Biol., 153, 63-76.

4. Saheki, T., Ueda, A., Iizima, K., Yamada, N., Kobayashi, K., Takahashi, K., and Katsunuma, T. (1982): Argininosuccinate synthetase activity in cultured skin fibroblasts of citrullinemic patients. Clin. Chim. Acta, 118, 93-97.

5. Saheki, T., Nakano, K., Kobayashi, K., Itakura, Y., Sase, M., Hagihara, S., and Matuo, S. (1985): Analysis of the enzyme abnormality in eight cases of neonatal and infantile citrullinemia in Japan. J. Inher. Metab. Dis., 8, 155-156.

6. Sase, M., Kobayashi, K., Imamura, Y., Saheki, T., Nakano, K., Miura, S., and Mori, M. (1985): Level of translatable messenger RNA coding for argininosuccinate synthetase in the liver of the patients with quantitative-type citrullinemia. Hum. Genet., 69, 130-134.

Vol. 1, No. 2, 1986 
7. Kobayashi, K., Saheki, T., Imamura, Y., Noda, T., Inoue, I., Matuo, S., Hagihara, S., Nomiyama, H., Jinno, Y., and Shimada, K. (1986): Messenger RNA coding for argininosuccinate synthetase in citrullinemia. Am. J. Hum. Genet., 38 (in press).

8. Morrow, G., Barness, L.A., and Efron, M.L. (1967): Citrullinemia with deficient urea production. Pediatrics, 40, 565-574.

9. Shih, V.E. (1976): Hereditary urea-cycle disorders, in The Urea Cycle, ed. by Grisolia, S., Baguena, R., and Mayor, F., John Wiley and Sons, New York, pp. 367-414.

10. Saheki, T., Sase, M., Nakano, K., and Yagi, Y. (1985): Arginine metabolism in citrullinemic patients, in Guanidines, ed. by Mori, A., Cohen, B.D., and Lowenthal, A., Plenum Press, New York, London, pp. 149-158.

11. Yamauchi, M., Kitahara, T., Fujisawa, K., Kameda, H., Takasaki, S., Komori, R., Saheki, T., Katsunuma, T., and Katunuma, N. (1980): An autopsied case of hypercitrullinemia in adult caused by partial deficiency of liver argininosuccinate synthetase. Acta Hepatol. Jpn., 21, 326-334.

12. Yamada, N., Fukui, M., Ishii, K., Shibata, H., Okabe, H., Ohomiya, H., Matsunobu, A., and Nishizima, M. (1980): A case of adult form hypercitrullinemia with consciousness disturbance and marked hypertransaminasenemia after delivery. Gastroenterol. Jpn., 77, 1655-1660.

13. Suzuki, Y., Yamamura, N., Nozawa, K., Akahane, Y., Kiyosawa, K., Nagata, A., Furuta, S., and Chiba, K. (1980): A case of adult-type congenital citrullinemia. Acta Hepatol. Jpn., 21, 1215-1221.

14. Oyanagi, K., Sogawa, H., Tsukazaki, H., Nakata, F., Tsuchiyama, A., Mitamura, A., and Mori, M. (1982): Juvenile hepatocerebral disease with citrullinemia. Report of a case. $J$. Clin. Pediatr., 30, 385-389.

15. Ishii, H., Nakamura, T., Inoue, K., Tsujimura, R., and Nomura, J. (1985): A case of adulttype citrullinemia. Mie Igaku, 28, 559-564.

16. Fukuda, S., Okawa, M., Yoshida, Y., Nara, H., Aizawa, M., and Saheki, T. (1985): A case of citrullinemia. Kan Tan Sui, 8, 439-446.

17. Itakura, Y., Tsuchiyama, A., Uetsuji, N., Tsukazaki, H., Nakata, F., Oyanagi, K., Nakao, T., and Tsugawa, S. (1984): A varient form of neonatal citrullinemia. J. Jpn. Pediatr. Soc., 88, 1684-1688.

18. Nakazawa, Y., Okino, E., Takuma, S., Okada, R., Takahashi, H., and Saheki, T. (1985): A case of citrullinemia. J. Jpn. Pediatr. Soc., 89, 1759-1767.

19. Akaboshi, I., Endo, F., Matsuda, I., and Saheki, T. (1983): Kinetic analysis of argininosuccinate synthetase in a variant form of citrullinaemia. J. Inher. Metab. Dis., 6, 36-39.

20. Funahashi, M., Kato, H., Shiosaka, S., and Nakagawa, H. (1981): Formation of arginine and guanidinoacetic acid in the kidney in vivo. J. Biochem., 89, 1347-1356.

21. Windmueller, H.G., and Spaeth, A.E. (1981): Source and fate of circulating citrulline. Am.J. Physiol., 241, E473-E480.

22. Saheki, T., Yagi, Y., Sase, M., Nakano, K., and Sato, E. (1983): Immunohistochemical localization of argininosuccinate synthetase in the liver of control and citrullinemic patients. Biomed. Res., 4, 235-238.

23. Yagi, Y., Saheki, T., Imamura, Y., Kobayashi, K., Sase, M., Nakano, K., Matuo, S., Inoue, I., Hagihara, S., and Noda, T.: The heterogeneous distribution of argininosuccinate synthetase in the liver of quantitative-type citrullinemic patients. Its specificity and possible clinical implications. J. Clin. Invest. (submitted). 